\title{
Reduced chromogranin A cell density in the ileum of patients with irritable bowel syndrome
}

\author{
MAGDY EL-SALHY ${ }^{1,2}$, INGVILD HAUKAAS WENDELBO ${ }^{1,2}$ and DORIS GUNDERSEN ${ }^{3}$ \\ ${ }^{1}$ Section for Gastroenterology, Department of Medicine, Stord Helse-Fonna Hospital, Stord; ${ }^{2}$ Section for Gastroenterology, \\ Institute of Medicine, University of Bergen, Bergen; ${ }^{3}$ Department of Research, Helse-Fonna, Haugesund, Norway
}

Received October 30, 2012; Accepted January 29, 2013

DOI: $10.3892 / \mathrm{mmr} .2013 .1325$

\begin{abstract}
Irritable bowel syndrome (IBS) is a common disorder that considerably reduces the quality of life and productivity of patients. Chromogranin $\mathrm{A}(\mathrm{CgA})$ is a common marker for endocrine cells. $\mathrm{CgA}$ cell density has been reported to be reduced in the duodenum and colon of IBS patients. This study was undertaken to investigate $\mathrm{CgA}$ cell density in the ileum of these patients. The study involved 98 patients with IBS, according to the Rome III Criteria ( 77 females and 21 males, with an average age of 35 years). In total, 35 patients had diarrhoea-predominant symptoms (IBS-D), 32 had constipation-predominant symptoms (IBS-C), and 31 had a mixture of both diarrhoea and constipation (IBS-M). In this study, 27 subjects were used as controls (16 females and 11 males, with an average age of 52 years). Colonoscopies were performed on the patients and controls and biopsies were obtained from the ileum. Sections were immunostained with the avidin-biotin complex (ABC) for $\mathrm{CgA}$ and quantified using computerized image analysis. The $\mathrm{CgA}$ density in the controls was $63.2 \pm 4.4$ (mean \pm SEM), for all IBS patients it was $28.6 \pm 2.1$, for IBS-D it was $28.8 \pm 3.4$, for IBS-M it was $26.5 \pm 3.9$ and for IBS-C it was $30.3 \pm 3.7$. There was a statistically significant difference between the controls and all IBS patients (IBS-D, IBS-M and IBS-C; P<0.0001 for all). The present study showed that $\mathrm{CgA}$ cell density in the ileum of IBS patients was reduced, regardless of subtype. Thus, it appears that there is endocrine cell depletion in both the small and large intestine of IBS patients, whereas IBS is normally considered to be a functional condition without any detectable abnormalities. The present finding lends support to the suggestion that IBS is caused by a biological abnormality, and intestinal $\mathrm{CgA}$ cell density may be used as a biological marker for the diagnosis of IBS.
\end{abstract}

Correspondence to: Professor Magdy El-Salhy, Section for Gastroenterology, Department of Medicine, Stord Helse-Fonna Hospital, 5409 Stord, Norway

E-mail: magdy.el-salhy@helse-fonna.no

Key words: chromogranin A, computer image analysis, immunohistochemistry, ileum, irritable bowel syndrome

\section{Introduction}

Irritable bowel syndrome (IBS) is a common chronic gastrointestinal disorder affecting $10-15 \%$ of the western population, with a female predominance (1-3). IBS is characterized by abdominal discomfort or pain associated with altered bowel habits, and often bloating and abdominal distension (1-3). The degree of symptoms varies between patients, from tolerable to severe, with a considerable reduction to quality of life and productivity (1-6). Besides the increased morbidity caused by IBS, this disorder also represents an economic burden to society in different forms, including increased sick leave and overconsumption of healthcare resources (6-8). However, IBS is not known to be associated with the development of serious diseases or excess mortality $(9,10)$. IBS patients are sub-grouped on the basis of differences in the predominant bowel pattern: diarrhoea-predominant (IBS-D), constipationpredominant (IBS-C), or a mixture of both diarrhoea and constipation (IBS-M) (1). It has been reported that approximately one third of patients have IBS-D, one third have IBS-C, and the remainder have IBS-M (1).

Several abnormalities in the endocrine cells of the gastrointestinal tract have been reported in IBS patients (11-24). These abnormalities have been suggested to be important in the pathogenesis of IBS $(1,25)$. The endocrine cells observed in the proximal (duodenum) and distal (terminal ileum) small intestine are quite different (25). Both the duodenum and terminal ileum comprise serotonin and somatostatin cells (25), whereas the duodenum contains cholecystokinin (CCK), secretin and gastric inhibitory polypeptide (GIP) cells, while the terminal ileum contains peptide YY (PYY), pancreatic polypeptide (PP) and enteroglucagon cells (25). The difference in endocrine cell composition reflects the different functions of the proximal and distal small intestine. The endocrine cells in the terminal ileum of patients with IBS have yet to be investigated. This may be due to the technical difficulties involved in obtaining biopsies from the ileum of these patients, caused by a long looping colon combined with visceral hypersensitivity in IBS patients.

Chromogranin $\mathrm{A}(\mathrm{CgA})$ is a $68 \mathrm{kDa}$ protein comprising 439 amino-acid residues. $\mathrm{CgA}$ is co-stored and co-released with monoamines and peptide hormones of the adrenal medulla, pituitary gland, parathyroid, thyroid C-cells, pancreatic islets, endocrine cells of the gastrointestinal tract and sympathetic 
nerves $(9,10), \mathrm{CgA}$ is considered to be a general marker for gut endocrine cells and endocrine tumours $(9,10,26)$. CgA cell density has been reported to be lowered in the duodenum and colon, but not in the rectum $(27,28)$. This study was undertaken in order to investigate a possible abnormality in the density of the endocrine cells, as detected by $\mathrm{CgA}$, in the ileum of IBS patients.

\section{Materials and methods}

Patients and controls. In total, 98 patients with IBS according to the Rome III Criteria were included in this study (http://www. romecriteria.org) (29). These patients included 77 females and 21 males with an average age of 35 years (range, 18-66 years). In total, 35 patients had IBS-D, 31 had IBS-M and 32 had IBS-C. All 98 patients had symptoms for many years and could not associate the onset of IBS symptoms with any event, particularly gastrointestinal or other infections. The patients underwent complete physical examinations and were investigated with blood tests: full blood count, electrolytes, calcium, inflammatory markers, liver tests and thyroid function tests. They underwent further gastroscopy with duodenal biopsies, in order to exclude celiac disease.

In total, 27 subjects who underwent colonoscopy with terminal ileum biopsies were used as controls. Of these, 20 subjects underwent a colonoscopy due to gastrointestinal bleeding, where the source of bleeding was identified to be haemorrhoids (18) or angiodysplasia (2). Seven of the subjects were examined due to health worries caused by a relative having been diagnosed with colon carcinoma. The control group consisted of 16 females and 11 males with an average age of 52 years (range, 20-69 years).

The study was performed in accordance with the Declaration of Helsinki and was approved by the local Committee for Medical Research Ethics. All the subjects gave oral and written consent.

Colonoscopy. Colonoscopies were performed on both patients and controls and biopsies were taken from the ileum and the right (cecum, ascending and right part of transverse colon) and left colon (left part of transverse, descending and sigmoid colon). Biopsies were fixed in $4 \%$ buffered paraformaldehyde overnight, embedded in paraffin and cut into 5- $\mu \mathrm{m}$ sections.

Histopathology and immunohistochemistry. The sections were stained with haematoxylin and eosin and immunostained with the avidin-biotin complex (ABC) method using the Vectastain $\mathrm{ABC}$ kit and the 3,3'-diaminobenzidine (DAB) peroxidase substrate kit (Vector Laboratories, Burlingame, CA, USA). The primary antibody used was monoclonal mouse anti-N-terminal purified CgA (Dako, Carpinteria, CA, USA; code no. M869).

Computerized image analysis. Analysis was conducted using Olympus software cell ${ }^{\wedge} \mathrm{D}$. When using $\mathrm{x} 40$ objectives, the frame (field) on the monitor represents an area of $0.14 \mathrm{~mm}^{2}$ of the tissue. The number of $\mathrm{CgA}$ immunoreactive cells and the area containing the epithelial cells were measured in each field. Measurements were taken in 10 randomly chosen fields for each individual. The data from the fields were tabulated
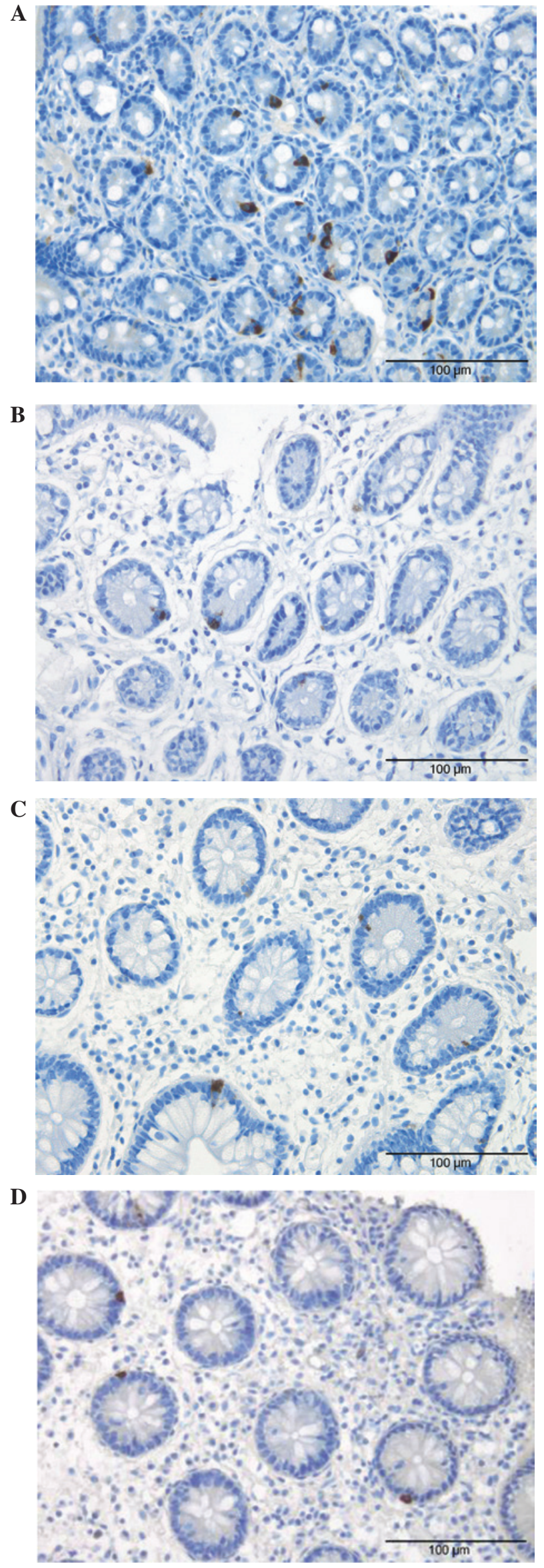

Figure 1. Chromogranin A ( $\mathrm{CgA})$-immunoreactive cells in the ileum of (A) a control subject and of a patient with (B) diarrhoea-predominant symptoms (IBS-D), (C) a mixture of both diarrhoea and constipation (IBS-M) and (D) constipation-predominant symptoms (IBS-C). 


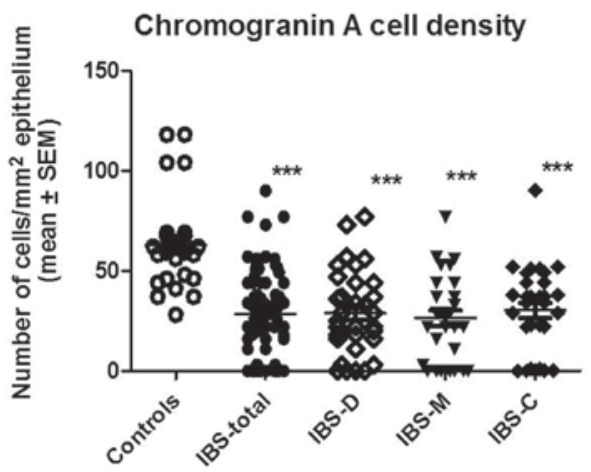

Figure 2. Chromogranin A $(\mathrm{CgA})$-immunoreactive cell density in the ileum of controls, all irritable bowel syndrome (IBS) patients and IBS sub-types. ${ }^{* * * *} \mathrm{P}<0.0001$.

and the number of cells $/ \mathrm{mm}^{2}$ of the epithelium were computed and automatically statistically analysed. The immunostained sections of IBS patients and controls were coded and mixed, and measurements were made without knowledge of the identity of the sections.

Statistical analysis. Comparison between controls, IBS patients and IBS sub-groups was performed by the nonparametric ANOVA test with Dunnett's multiple comparison test as a post hoc test.

\section{Results}

Colonoscopy, histopathology and immunohistochemistry. The colons of the patients and control subjects were macroscopically normal. The ileum was also macroscopically normal, with the exception of one control subject and three of the patients, where lymphoid hyperplasia was observed. Lymphoid hyperplasia is a common finding in young individuals without any pathological relevance.

Histopathological examination of the colon biopsies revealed normal histology, excluding microscopic colitis. Histopathological examination of the ileum revealed normal histology and confirmed the finding of lymphoid hyperplasia in the individuals mentioned above. $\mathrm{CgA}$ cells were mainly located in the crypts (Fig. 1); these cells were basket- or flask-shaped.

Computerized image analysis. The $\mathrm{CgA}$ density in the controls was $63.2 \pm 4.4$ (mean \pm SEM), in all IBS patients it was 28.6 \pm 2.1 , in IBS-D patients it was $28.8 \pm 3.4$, in IBS-M patients it was $26.5 \pm 3.9$ and in IBS-C patients it was $30.3 \pm 3.7$ (Fig. 2). There was a statistically significant difference between controls and all IBS patients (IBS-D, IBS-M and IBS-C; P<0.0001 for all).

\section{Discussion}

The age and gender of the patients and healthy controls used in this investigation did not match completely. The control subjects included in the present study were slightly older and the proportion of males to females was higher. It is not easy to find healthy volunteers matching the age and gender of the patients that are willing to be subjected to bowel preparation prior to colonoscopy and colonoscopy. One must be patient and wait for healthy subjects that undergo this examination for other reasons. However, in previous studies, age and gender have been found to have no effect on the density of intestinal endocrine cells in adults $(30,31)$. The medical history of the IBS patients studied demonstrates that there is no association between the onset of IBS symptoms and gastrointestinal infection and, consequently, the patients included in this study suffer from sporadic IBS.

This study demonstrates that $\mathrm{CgA}$ cell density in the ileum of IBS patients is reduced, regardless of the subtype. It has been reported previously that $\mathrm{CgA}$ cell density is also reduced in the duodenum and colon of IBS patients (27). Thus, it appears there is endocrine cell depletion in the small and large intestine of IBS patients. This is notable, as IBS has been considered to be a functional condition without detectable abnormalities. The present finding lends support to the suggestion that $\mathrm{CgA}$ cell density may be used as a biological marker for the diagnosis of IBS $(1,17,27)$. This would be advantageous, as currently there are no biochemical, histopathological or radiological diagnostic tests for IBS. At present, the diagnosis of IBS is based on symptom assessment.

The ileum contains the same types of endocrine cells as the large intestine, serotonin, PYY, PP, somatostatin and enteroglucagon cells. This is unsurprising as the ileum, similar to the large intestine, contributes to the absorption of water and electrolytes from the lumen and regulates the passage of faeces. As mentioned previously, $\mathrm{CgA}$ cell density represents the total endocrine cell content of the ileum and more studies are required in order to determine which endocrine cell type is affected.

In conclusion, the present study demonstrates that the total number of endocrine cells is reduced in the ileum of IBS patients. Furthermore, it confirms that the endocrine cells are depleted in the small and large intestine of IBS patients.

\section{Acknowledgements}

This study was supported by a grant from Helse-Fonna.

\section{References}

1. El-Salhy M, Gundersen D, Hatlebakk JG and Hausken T (eds): Irritable Bowel Syndrome: Diagnosis, Pathogenesis \& Treatment Options. Nova Science Publishers Inc., New York, NY, 2012

2. Thompson WG: A world view of IBS. In: Irritable Bowel Syndrome: Diagnosis and Treatment. Camilleri M and Spiller R (eds). Saunders, Philadelphia and London, pp17-26, 2002.

3. Drossman DA, Li Z, Andruzzi E, et al: U.S. householder survey of functional gastrointestinal disorders. Prevalence, sociodemography, and health impact. Dig Dis Sci 38: 1569-1580, 1993.

4. Hungin AP, Whorwell PJ, Tack J and Mearin F: The prevalence, patterns and impact of irritable bowel syndrome: an international survey of 40,000 subjects. Aliment Pharmacol Ther 17: 643-650, 2003.

5. Wilson S, Roberts L, Roalfe A, Bridge P and Singh S: Prevalence of irritable bowel syndrome: a community survey. Br J Gen Pract 54: 495-502, 2004.

6. Whitehead WE, Burnett CK, Cook EW III and Taub E: Impact of irritable bowel syndrome on quality of life. Dig Dis Sci 41: 2248-2253, 1996

7. Everhart JE and Renault PF: Irritable bowel syndrome in officebased practice in the United States. Gastroenterology 100: 998-1005, 1991. 
8. Harvey RF, Salih SY and Read AE: Organic and functional disorders in 2000 gastroenterology outpatients. Lancet 1: 632-634, 1983

9. Taupenot L, Harper KL and O'Connor DT: The chromograninsecretogranin family. N Engl J Med 348: 1134-1149, 2003.

10. Wiedenmann B and Huttner WB: Synaptophysin and chromogranins/secretogranins - widespread constituents of distinct types of neuroendocrine vesicales and new tools in tumor diagnosis. Virchows Arch B Cell Pathol Incl Mol Pathol 58: 95-121, 1989.

11. El-Salhy M, Lillebø E, Reinemo A and Salmelid L: Ghrelin in patients with irritable bowel syndrome. Int J Mol Med 23 703-707, 2009

12. Sjölund K, Ekman R and Wierup N: Covariation of plasma ghrelin and motilin in irritable bowel syndrome. Peptides 31: 1109-1112, 2010.

13. Dizdar V, Spiller R, Singh G, Hanevik K, Gilja OH, El-Salhy M and Hausken T: Relative importance of abnormalities of CCK and 5-HT (serotonin) in Giardia-induced post-infectious irritable bowel syndrome and functional dyspepsia. Aliment Pharmacol Ther 31: 883-891, 2010.

14. El-Salhy M, Vaali K, Dizdar V and Hausken T: Abnormal small intestinal endocrine cells in patients with irritable bowel syndrome. Dig Dis Sci 55: 3508-3513, 2010.

15. El-Salhy M, Gundersen D, Ostgaard H, Lomholt-Beck B, Hatlebakk JG and Hausken T: Low densities of serotonin and peptide YY cells in the colon of patients with irritable bowel syndrome. Dig Dis Sci 57: 873-878, 2012.

16. El-Salhy M, Gundersen D, Hatlebakk JG and Hausken T: Abnormal rectal endocrine cells in patients with irritable bowel syndrome. Submitted, 2012.

17. El-Salhy M, Seim I, Chopin L, Gundersen D, Hatlebakk JG and Hausken T: Irritable bowel syndrome: the role of gut neuroendocrine peptides. Front Biosci (Elite Ed) 4: 2783-2800, 2012.

18. Coates MD, Mahoney CR, Linden DR, Sampson JE, Chen J, Blaszyk H, Crowell MD, Sharkey KA, Gershon MD, Mawe GM and Moses PL: Molecular defects in mucosal serotonin content and decreased serotonin reuptake transporter in ulcerative colitis and irritable bowel syndrome. Gastroenterology 126: 1657-1664, 2004.

19. Wang SH, Dong L, Luo JY, Gong J, Li L, Lu XL and Han SP: Decreased expression of serotonin in the jejenum and increased numbers of mast cells in the terminal ileum in patients with irritable bowel syndrome. World J Gastroenterol 13: 6041-6047, 2007.
20. Park JH, Rhee PL, Kim G, Lee JH, Kim YH, Kim JJ, Rhee JC and Song SY: Enteroendocrine cell counts correlated with visceral hypersensitivity in patients with diarrhoea-predominant irritable bowel syndrome. Neurogastroenterol Motil 18: 539-546, 2006.

21. Dunlop SP, Jenkins D and Spiller RC: Distinctive clinical, psychological and histological feature of postinfective irritable bowel syndrome. Am J Gastroenterol 98: 1578-1583, 2003.

22. Lee KJ, Kim YB, Kim JH, Kwon HC, Kim DK and Cho SW: The alteration of enterochromaffin cell, mast cell, and lamina propria T lymphocyte numbers in irritable bowel syndrome and its relationship with psychological factors. J Gastroenterol Hepatol 23: 1689-1694, 2008.

23. Spiller RC, Jenkins D, Thornley JP, Hebden JM, Wright T, Skinner M and Neal KR: Increased rectal mucosal enteroendocrine cells, T lymphocytes, and increased gut permeability following acute Campylobacter enteritis and in post-dysenteric irritable bowel syndrome. Gut 47: 804-811, 2000.

24. Kim HS, Lim JH, Park H and Lee SI: Increased immunoendocrine cells in intestinal mucosa of postinfectious irritable bowel syndrome patients 3 years after acute Shigella infection - an observation in small case control study. Yonsei Med J 51: 45-51, 2010.

25. Dunlop SP, Coleman NS, Blackshaw E, Perkins AC, Singh G, Marsden CA and Spiller RC: Abnormalities of 5-hydroxytryptamine metabolism in irritable bowel syndrome. Clin Gastroenterol Hepatol 3: 349-357, 2005.

26. Deftos LJ: Chromogranin A: its role in endocrine function and as an endocrine and neuroendocrine tumor marker. Endocr Rev 12: 181-187, 1991

27. El-Salhy M, Lomholt-Beck B and Hausken T: Chromogranin as a tool in the diagnosis of irritable bowel syndrome. Scand J Gastroenterol 45: 1435-1439, 2010.

28. El-Salhy M, Mazzawi T, Gundersen D and Hausken T: Chromogranin A cell density in the rectum of patients with irritable bowel syndrome. Mol Med Rep 6: 1223-1225, 2012.

29. Longstreth GF, Thompson WG, Chey WD, Houghton LA, Mearin F and Spiller RC: Functional bowel disorder. Gastroenterology 130: 1480-1491, 2006.

30. Sandström O and El-Salhy M: Aging and endocrine cells of human duodenum. Mech Ageing Dev 108: 39-48, 1999.

31. Sandström O and El-Salhy M: Human rectal endocrine cells and aging. Mech Ageing Dev 108: 219-226, 1999. 